\title{
Identifying and ranking new product factors of fashion industry (case study Iranian menswear brand)
}

\author{
Siamak Nazemi ${ }^{1, *}$, Roohollah Bagherzade ${ }^{2}$ \\ 1 Fashion and Textile Design Department of Islamic Azad University of South Tehran, Tehran, Iran \\ 2 Institute for Advanced Textile Materials and Technologies (ATMT), Amirkabir University of Technology, Tehran, \\ Iran \\ *Corresponding author E-mail address: nazemi.textile@gmail.com
}

\section{INFO}

CDAPT, ISSN 2701-939X

Peer reviewed article

2021, Vol. 2, No. 1, pp. 40-48

DOI 10.25367/cdatp.2021.2.p40-48

Received: 18 May 2021

Accepted: 15 June 2021

Available online: 26 June 2021

\begin{abstract}
In fashion industry, creative ideas and new products appear in new collections of brands presented in several ways, such as fashion week, exhibition etc. Iranian menswear also had the same strategy, but because of features of their customers, usually they use same designs and products in their new collections. Achieving new products in fashion industry can be related to design and technology aspect. Here we are looking for important factors affecting new products in Iranian menswear and also aiming at understanding which strategy are utilized in these product lines. Firstly this is done by gathering data from the Iranian Fashion association and 3 big Iranian menswear brands, secondly by interviews with experts from Iranian menswear brands, looking for answers of the study question. Twelve factors released from literature of study are divided in four sections: fabric sector, garment and accessories sector, and market sector. In 2010decade, Iranian menswear brands focused on the technology factor in their new products, but during recent years, they changed their mind and now change direction to design departments. These phenomena happen due to the impact of social media on Iranian culture, with social media changing the behavior of the Iranian customer. Generally, accessing the directors of menswear brands was difficult, and during their interview they tried to hide some information. New products were an important factor in increasing market of any menswear brand. This study helps them to utilize the best strategy depending on their customers and market. This study confirms a new product's impact on customer behavior and culture which could be difference with time.
\end{abstract}

Keywords

New product,

Ranking,

TOPSIS,

Fashion,

Menswear

(c) 2021 The authors. Published by CDAPT.

This is an open access article under the CC BY-NC-ND license https://creativecommons.org/licenses/ peer-review under responsibility of the scientific committee of the CDAPT. 


\section{Introduction}

Fashion industry is based on new products. The first generation of industrialization began from the weaving industry, which is related to fashion, during this time the most important factor for researchers and developers in terms of product quantity. After this time, in the $19^{\text {th }}$ century haute couture was founded by the French designer Charles Fedrick Worth, also called the father of haute couture. In this time, creations of designers were most important factors for new products in fashion industries. Early in the $20^{\text {th }}$ century, the famous fashion designers such as Chanel, Paul Poiret, Jeanne Lanvin, Elsa Schiaparelli, etc., changed the taste of fashion by their creative design. They also represented life style behind their fashion design. One of the famous designers was Chanel. After the Second World War, technology entered the fashion industry since one of the important materials that significantly changed this field was the newly produced polyvinylchloride (PVC). Those fabrics changed the collection atmosphere of fashion designer like Pierre Cardin [1]

Today, new products in the fashion industry appear in the design of companies or utilizing new technologies in their products. Several fashion designers work on creating their designs, such as Rei Kawakubo, Ralph \& Russo, Jeremy Scott etc. Their customers engage to new collections which they launch to the market; their followers are looking for each fashion week and fashion events in which they participate, their strategy based on customer engagement. They had several departments for designing their clothes, involving markets, suppliers, and designing [2].

The Iranian fashion industry began at least 200 years ago when an Iranian king visited London and recognized the taste of fashion in European countries. After World War 2, the former Iranian regime paid attention to the fashion style, visible by the brides of the former Shah's costume in their ceremony being from Dior, but after the Islamic revolution, fashion become forbidden for people. After some reforms in the government resolution, fashion became more accessible to the people, but in Islamic form. In 2005, the Fashion Association was established, showing a first idea of attention to fashion and life style after the Islamic revolution.

Another kind of new product in fashion industries is based on new technologies, such as nanomaterials, Gore-Tex, Coolmax etc., purchased by brands such as Nike, Adidas, Puma etc. who used this kind of technology especially in sportswear. They focus on the market, suppliers, R\&D centers which include scientists and designers.

For customers all around the world, some factors for choosing clothes are identical: budget, function, brand's reputation, culture, fashion trends, and quality. In the Iranian market environment, factors to choose clothes were the same, but some parameters were different during times, for example, after tight sanctions, when the budgets of people reduce, this became a major parameter. During these times, another parameter change took place by using smartphones, influencing culture and behavior of customers. Today people know more about the latest technologies launched in the world, during fashion weeks and other events.

In the $4^{\text {th }}$ generation of industrialization, social media and social networks play significant roles in all aspects of our lives. The fashion industry is affected by this revolution especially in some countries like Iran, because they had a different type of culture. Social media impacted their life and changed their behavior and culture, causing different reactions especially in men society.

\section{Background of the study}

The background of this study is given by many previous studies. Marco Brambilla et al. [3] worked on the effect of social media on the Milan Fashion Week, investigating Instagram posts and responds of brand followers, also concluding that brands could be subdivided in four categories with respect to social media. Geissinger and Laurell [4] studied the impact of social media on the Stockholm fashion week, observing social behavior of Sweden during the fashion week by choosing seven brands and 
investigated the constellation of participating companies. They concluded that social media increasingly reached consumer realm.

Bandinelli et al. [5] investigated new product developments in the fashion industry. For this purpose, eight Italian companies were analyzed by case study methodology. They concluded that three different stages were used for new product development (NPD) in fashion industry organization, process and knowledge management. In addition, customer services, roles of suppliers and competitors were important factors. Gherardi and Murgia [6] studied the staging precariousness of Milan fashion week, investigating the social movement during contemporary times and concluding that social changing affected the fashion week.

Entwistle and Rocamora [7] worked on fashion materialized in London fashion week by investigating the buying strategies and behavior of customers in the London Fashion Week. They concluded that several players are active in this field, thus relations between them were important, especially arts and commerce. Dewi et al [8] investigated the risk management during NPD in fashion industries, using data from three different fashion companies and analyzing them by Failure Mode Effect and Critically Analysis (FMECA) and House of Risk (HOR). Their study showed critical risk events, critical risks agents and risk mitigation strategies.

Goworek et al. [9] studied sustainable fashion during new product development in the UK by interviewing stockholders in the fashion sector. By analyzing thematically a range of responses, they concluded that fashion sustainability occurred through an improved knowledge, skills, process and infrastructure, if managerial decisions were taken to reduce barriers to longevity and to enhance the agency of NPD teams in this respect.

Zhang et al. [10] worked on fashions cewebrities and scales in new product development, collecting data from Chinese companies by a survey. The study indicated that fashion companies have five attributes: attractiveness, trustworthiness, expertise, interactivity, and intimacy. These attributes were found to exert varying impacts on the product design, production and commercialization, thereby influencing the purchase intention differently.

Bertola and Teunissen [11] investigated the $4^{\text {th }}$ generation of industrialization and its effect on innovation in fashion industries. Using a literature review, they concluded that digital transformation, properly driven, could reshape the fashion industry into a more sustainable and truly customer-driven business. But they also underlined criticalities and slowness of adoption by traditional established brands and companies.

Cazeri et al. [1] investigated the product develop process (PDP) based on 37 academic papers related to PDP, dividing them into five main categories. They found that $27 \%$ of them were related to design performance, $5.5 \%$ to human resources, $62 \%$ were related to knowledge resources, $5.5 \%$ to financial performance and $0 \%$ related to literature review. Svendsen et al. [2] investigated marketing strategies and customer involvement in product development. They concluded that two facets of marketing strategy, i.e. product differentiation and competitor orientation, positively influenced the customer involvement. Furthermore, specific investments dedicated to the relationship were also positively related with customer involvement, and customer involvement increased customer profitability.

Lim et al. [12] investigated the strategic impact of new product development on the export involvement, and they concluded that supports of the argument that faster new product development capability must be augmented for companies looking for a higher degree of export involvement. In addition, they underlined the importance of integrating the marketing, R\&D, and engineering functions to develop competitive advantages. Lindman [13] studied new product development strategies of SMEs, finding that SMEs tend to lack a long-run perspective and miss a clear role of new products in business strategy, while the goals regarding future products were not fully clear. In 2005, Pitta [14] worked on the market environmental system strategies of new products in China and concluded that information and action approach to new product developers were engaged in global marketing. 
Fantazy and Salem [15] worked on the influence of strategy and flexibility in R\&D on the improvement of efficiency. They revealed a direct positive effect from the strategy on NPD. Their findings also indicated a direct positive association between NPD and performance and revealed that the total effect (direct and indirect) positively influenced the performance.

Hong and Ghobakhloo [16] worked on the effect of IT and new products on the Iranian markets. They showed that IT leveraging competence in NPD and NPD effectiveness were valuable key capabilities that transformed the value of IT resources to a company's performance for Iranian small businesses. Investments in technical and human IT resources had positive effects on the development of NPD capabilities and thus a better performance in the surveyed companies.

Identifying important factors of NPD was done by literature reviewing, during this process some references were used connected with this paper. The factors investigated are illustrated in Table 1, in which all items reveal direct connections to each other $[2,15]$. In this paper, firstly important factors for new product development in Iran fashion industries are identified, before ranking these factors by questionnaires form experts, suppliers and customers of menswear brands using the TOPSIS method, adopted for Iranian environment, and analysing them.

\section{Research methodology}

In this study, three big Iranian companies in the field of menswear were chosen from data of Iran fashion association center. The important criterion considered for collecting these companies was the amount of selling in a year and the number of chain stores across the country. Table 1 shows the brands $A, B, C$ in Iran menswear industries.

Table 1. Comparison of menswear brands $A, B, C$.

\begin{tabular}{ccc}
\hline Name of company & Number of stores & $\begin{array}{c}\text { Amount of selling per year } \\
\text { (million dollars) }\end{array}$ \\
\hline A & 30 & 40 \\
\hline B & 25 & 33 \\
\hline C & 21 & 26 \\
\hline
\end{tabular}

By interviews with the commercial director, the art director and the CEO of the three brands mentioned above, 12 factors were extracted which were important for new products. The factors in Table 2 were at least three times mentioned in the interviews.

Surveys were also sent to experts in menswear industries to collect their responses. From the 305 people asked (all menswear factories in Tehran city from data of Iran Fashion Association including SEMs and big companies), just 110 responded, i.e. the confidence level is $89 \%$ and the margin of error $6.5 \%$ for this this confidence level. On the Likert scale used in the questionnaires, each expert chose between 1 and 5 for any question ( 1 means low effect of that parameter on new product design in menswear and 5 means high effect of that criterion). Likert-type or frequency scales use fixed choice response formats and are designed to measure attitudes or opinions. These ordinal scales measure levels of agreement/disagreement.

A Likert-type scale considers that capability of experience is linear, i.e., on a progression from strongly agreeing to strongly disagreeing, and assumes that conditions can be measured. In this study, the questions offered a choice of five answers with the objective point being neither agree nor disagree. Then this data were used for measuring responses in questionnaires. 
Table 2. Important factors extracted from interviews with brands $A, B, C$.

\begin{tabular}{ccc} 
Item & Factor & Responder \\
\hline $\mathbf{1}$ & Choosing fabric & All art directors + CEO of brand A \\
\hline $\mathbf{2}$ & Choosing accessories & All art directors \\
\hline $\mathbf{3}$ & R\&D department & All CEOs + commercial directors of A and B \\
\hline $\mathbf{4}$ & Fabric design & All art directors + CEOs \\
\hline $\mathbf{5}$ & Market demand & All commercial directors + CEOs \\
\hline $\mathbf{6}$ & Customer behavior & All commercial directors + CEOs \\
\hline $\mathbf{7}$ & Industry equipment & All CEOs \\
\hline $\mathbf{8}$ & Supplier ability & All CEOs + arts directors \\
\hline $\mathbf{9}$ & Design department & All arts directors \\
\hline $\mathbf{1 1}$ & Economic conditions & All commercial directors + CEOs \\
\hline $\mathbf{1 2}$ & Government law \& resolution & All responders \\
\hline
\end{tabular}

Table 3. Average evaluation of experts.

\begin{tabular}{ccc} 
Item & Factor & Experts \\
\hline $\mathbf{1}$ & Choosing fabric & 4.5 \\
\hline $\mathbf{2}$ & Choosing accessories & 4.3 \\
\hline $\mathbf{3}$ & R\&D department & 4.4 \\
\hline $\mathbf{4}$ & Fabric design & 4.2 \\
\hline $\mathbf{5}$ & Market demand & 4.2 \\
\hline $\mathbf{6}$ & Customer behavior & 4.0 \\
\hline $\mathbf{7}$ & Industry equipment & 3.9 \\
\hline $\mathbf{8}$ & Supplier ability & 4.0 \\
\hline $\mathbf{9}$ & Design department & 3.8 \\
\hline $\mathbf{1 0}$ & Economic condition & 3.7 \\
\hline $\mathbf{1 1}$ & Government law \& resolution & 3.6 \\
\hline $\mathbf{1 2}$ & Social media influence & 3.5 \\
\hline
\end{tabular}


$85 \%$ of the responders were female and $15 \%$ were male (most responder was female because there are more female than male workers and buyers in Iranian market). The education level of the responders was $3 \% \mathrm{PhD}, 10 \% \mathrm{MBA}, 10 \%$ Master of Arts, $62 \%$ Bachelor of Art and $15 \%$ without education level. Age's comparison of the responders shows that $25 \%$ of them are below $30,30 \%$ of them are between 30 and 40 years old, 35\% of them are between 40 and 50 years old, and $10 \%$ of them are above 50 years. Further, $70 \%$ of them had less than ten years of experience, $20 \%$ of them had $10-20$ years of experience, $7 \%$ of them had $20-30$ years of experience, and $3 \%$ of them had more than 30 years of experience. In Table 3, the average answers of the responders are illustrated.

For sorting the criteria questioned in the survey, the Technique for Order of Preference by Similarity to Ideal Solution (TOPSIS) is used. TOPSIS is used for changing quality to quantity variables and helps to understand the effects more easily. This technique is based on similarities and differences to the positive ideal solution (PIS) and negative ideal solution (NIS) [17]. In this work, multi-criterial decision analysis (MCDA) methods are used. The TOPSIS process has six steps for ranking each item [18]:

Step 1: Constructing the decision matrix which is created from 110 alternatives (amounts of experts in menswear section that responded to our questionnaires) and 12 factors (extracted from interview with arts director, commercial directors and CEOs of 3 major brands in Iran).

$$
\mathrm{D}=\left[\begin{array}{ccc}
A 11 & \cdots & A 112 \\
A 21 & \cdots & A 212 \\
A 31 & \cdots & A 312 \\
A 41 & \cdots & A 412 \\
\cdots & \cdots & \cdots \\
\cdots & \cdots & \cdots \\
A 1101 & \cdots & A 11012
\end{array}\right]
$$

where $\mathrm{A}_{\mathrm{ij}}$ is the response of the expert $i$ to question $j$, followed by rating alternative $A_{i}$ with respect to criterion $\mathrm{V}_{\mathrm{ij}}$ evaluated by an expert, and $\mathrm{A}_{\mathrm{ij}}^{\mathrm{k}}=\left(\mathrm{Aa}_{\mathrm{ij}}^{\mathrm{k}}, \mathrm{b}_{\mathrm{ij}}^{\mathrm{k}}, \mathrm{c}_{\mathrm{ij}}^{\mathrm{k}}\right)$.

Step 2: Calculating the normalize decision matrix, for better understanding and comparison of strategy factor all values transformed to the same scale by Eq. 2 .

$$
r_{i j}=\frac{x_{i j}}{\sqrt{\sum_{i=1}^{110} x_{i j}^{2}}}
$$

Step 3. The weighted normalized decision matrix is shown as matrix V, calculated according to Eq. 3. In the matrix $\mathrm{V}$, for each staff of the 3 major menswear brand answer (CEOs, arts directors, commercial directors) all factor are weighted that were extracted from the interviews.

$$
\mathrm{V}=\left[v_{i j}\right]_{m * n}, \quad \mathrm{i}=\mathrm{I}, 2,3, \ldots ., 12 ; \quad \mathrm{j}=1,2,3, \ldots \ldots, 110 \quad \mathrm{~V}=\left[\begin{array}{ccc}
0.8 & \ldots & 0.7 \\
0.6 & \ldots & 0.6 \\
0.8 & \ldots & 0.6 \\
0.9 & \ldots & 0.7 \\
\ldots & \ldots & \ldots \\
\ldots & \ldots & \ldots \\
0.8 & \cdots & 0.8
\end{array}\right]
$$

Step 4: Determination of the PIS and NIS. According to the weighted normalized decision matrix, normalized positive TFNs are known as the elements $\sim m_{i j}$, and their ranges belong to the closed interval $[0,1]$. Then, we can define the PIS $A^{+}$and the NIS $A^{-}$as in Equations 5,6:

$$
\begin{aligned}
& A^{+}=\left(V_{1}^{+}, V_{2}^{+}, V_{3}^{+}, \ldots . ., V_{n}^{+}\right) \\
& A^{-}=\left(V_{1}^{-}, V_{2}^{-}, V_{3}^{-}, \ldots . ., V_{n}^{-}\right)
\end{aligned}
$$

where $V_{j}^{+}=(1,1,1$,$) and V_{j}^{-}=(0,0,0) \mathrm{j}=1,2,3, \ldots, \mathrm{n}$. 
Step 5: Calculating the distance of each alternative from PIS and NIS. The distances $\left(d_{i}^{+}\right.$and $\left.d_{i}^{-}\right)$of each alternative from $A^{+}$and $A^{-}$can be calculated by the area compensation method.

$$
\begin{aligned}
d_{i}^{+}=\sum_{j=1}^{n} d\left(v_{i j}, v_{j}^{+}\right), \quad \mathrm{i}=1,2, \ldots, \mathrm{m} \quad, \quad \mathrm{j}=1,2, \ldots \ldots, \mathrm{n} \\
d_{i}^{-}=\sum_{j=1}^{n} d\left(v_{i j}, v_{j}^{-}\right), \quad \mathrm{i}=1,2, \ldots, \mathrm{m} \quad, \quad \mathrm{j}=1,2, \ldots \ldots, \mathrm{n}
\end{aligned}
$$

Step 6: Firstly, Eq. 2 is calculated, then the weight of each factor asked from experts and their average is used for Eq. 4, before finally 3 variables are calculated from Eqs. 2, 4 and 7, to obtain the closeness coefficient and rank the order of alternatives.

\section{Result and discussion}

In the first stage of interviews with 3 member of 3 brands with different positions, the vision of the responders was important because each responder sorted criteria due to the stages of their career, for example all art director said that design of fabric and garment is important for new products, but commercial directors told that economic conditions and customer demands were important for them, while CEOs had a middle opinion, stating that both customer and design are important criteria for new products.

This study shows that for new products in menswear industries, four main categories including design, supplier, market, and output criterion could be defined, each of which was subdivided into 3 items. The effect of government and their decisions was important; during recent decades this parameter influenced industries, but usually their obstacle decision acted like barriers, while all data indicated that the hands of government should be cut from industry. Table 4 shows the criteria sorted by $\boldsymbol{d}_{\boldsymbol{j}}$.

Table 4. Sorted criteria after TOPSIS calculation.

\begin{tabular}{ccccc}
\hline Item & Question & $\boldsymbol{r}_{\boldsymbol{j}}$ & $\boldsymbol{d}_{\boldsymbol{j}}$ & $\boldsymbol{v}_{\boldsymbol{j}}$ \\
\hline $\mathbf{1}$ & Government influence & 0.021 & 0.0589 & 0.05301 \\
\hline $\mathbf{2}$ & Design department & 0.024 & 0.0555 & 0.0444 \\
\hline $\mathbf{3}$ & Supplier ability & 0.015 & 0.0532 & 0.03724 \\
\hline $\mathbf{4}$ & Customer need & 0.016 & 0.0529 & 0.02645 \\
\hline $\mathbf{5}$ & Economic condition & 0.022 & 0.0521 & 0.02084 \\
\hline $\mathbf{6}$ & Industry equipment & 0.021 & 0.0512 & 0.01536 \\
\hline $\mathbf{7}$ & Market demand & 0.019 & 0.0498 & 0.00996 \\
\hline $\mathbf{8}$ & Choosing fabric & 0.018 & 0.0490 & 0.0049 \\
\hline $\mathbf{9}$ & Choosing accessories & 0.023 & 0.0487 & 0.004383 \\
\hline $\mathbf{1 0}$ & Fabric design & 0.020 & 0.0480 & 0.00384 \\
\hline $\mathbf{1 1}$ & Garment design & 0.019 & 0.0456 & 0.003192 \\
\hline $\mathbf{1 2}$ & R\&D department & 0.019 & 0.0436 & 0.003052 \\
\hline
\end{tabular}

This study was organized during the coronavirus pandemic, all menswear companies during this time faced massive problems because of the downfall of selling statistic and lockdown problem. This phenomenon affected the responses of our expert answers, where some new notion such as online 
selling and $4^{\text {th }}$ generation of industrialization make sense recently. All 3 brands were less affected from the pandemic just for their amount of budget, warehouse system and number of staff, in comparison with other menswear companies, but because of less ceremonies and events during this time, they were nevertheless influenced by the coronavirus pandemic (all of them produce formal clothes such as suits).

According to Fig. 1 (which illustrates important factor in menswear), another factor which affected the study was sanctions. Iran economic face strict sanction during recent years and this caused government involvement in all detailed decisions for economy, these decisions and resolutions limiting the industry for free activity. These two factors should be considered during the study.

Most of the designers believe that menswear needs less innovation in contrast to womenswear, but this research shows that experts in menswear believe that innovation and design of products have an effect on new products in this field. This suggests changes for the new generation which lives in the age of social media, nowadays people being in this environment more often than before and hence changing their behavior. Ten years ago, menswear industries demanded to produce products with special features such as nano-finishing, antibacterial finishing etc., but today most of them believe that cut and design are more important than all special features. For this change in customer and designer behavior, R\&D departments become the last criterion. Life style becomes more important in recent times because of a new generation.

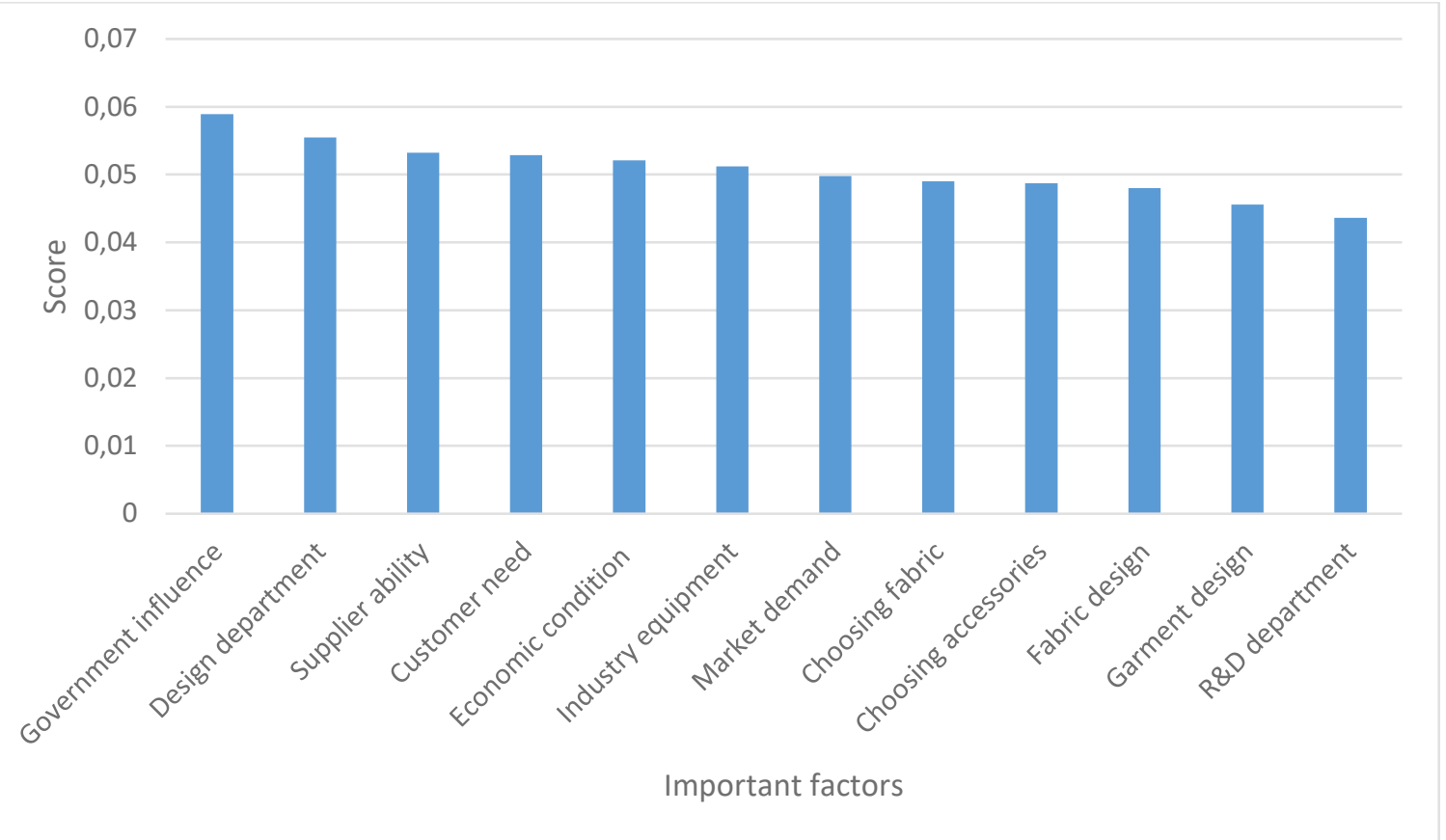

Figure 1. TOPSIS results of important factors

\section{Conclusion}

In this paper, important factors for new product developments in menswear are ranked. The results reveal that the influence of government is extremely high. This factor affected other factors, by changing fundamental conditions of economy which need tough political decision.

Twelve important factors were extracted in this study for improving new products in menswear industry. All factors extracted from interviews with experts were ranked by using the TOPSIS method.

On other hand, this study was done during 2020 in Tehran, facing the corona pandemic, sanctions, high inflation and reducing the Rial (Iran currency) value. These conditions make a good reason for government to put their hand in economic order and law. For further investigation we suggest the effect of the pandemic on the behavior of the government to be investigated. 


\section{References}

[1] Cazeri, G. T., Ordoñez, R., Anholon, R., Pereira, C., \& Rodrigues, E. Performance measurement in product development process (PDP): literature review and gaps for further research. Brazilian Journal of Operations \& Production Management 2019, 16, 550-561. DOI: https://doi.org/10.14488/BJOPM.2019.v16.n4.a1.

[2] Svendsen, M. F., Haugland, S. A., Grønhaug, K. and Hammervoll, T. Marketing strategy and customer involvement in product development. European Journal of Marketing 2011, 45, 513-530.

[3] Brambilla, M., Ceri, S., Daniel, F. and Donetti, G. Spatial analysis of social media response to live events: The case of the Milano Fashion Week. WWW'17 Companion: Proceedings of the 26th International Conference on World Wide Web Companion, April 2017, 1457.1462. DOI: https://doi.org/10.1145/3041021.3051698.

[4] Geissinger, A., Laurell, C. Tracing brand constellations in social media: the case of Fashion Week Stockholm. Journal of Fashion Marketing and Management 2018, 22, 35-48. DOI: https://doi.org/10.1108/JFMM-12-20160115.

[5] Bandinelli, R.; Rinaldi, R.; Rossi, M; Terzi, S. New product development in the fashion industry: an empirical investigation of Italian firms. International Journal of Engineering Business Management 2013, 5, 31. DOI: https://doi.org/10.5772/56841.

[6] Gherardi, S.; Murgia, A. Staging precariousness: The Serpica Naro catwalk during the Milan fashion week. Culture and Organization 2015, 21, 174-196. DOI: https://doi.org/10.1080/14759551.2013.837051.

[7] Entwistle, J.; Rocamora, A. The field of fashion materialized: a study of London Fashion Week. Sociology 2006, 40, 735-751. DOI: https://doi.org/10.1177/0038038506065158.

[8] Dewi, D. S., Syairudin, B. and Nikmah, E. N. Risk management in new product development process for fashion industry: case study in hijab industry. Procedia Manufacturing 2015, 4, 383-391. DOI: https://doi.org/10.1016/j.promfg.2015.11.054

[9] Goworek, H.; Oxborrow, L.; Claxton, S.; McLaren, A.; Cooper, T. and Hill, H. Managing sustainability in the fashion business: Challenges in product development for clothing longevity in the UK. Journal of Business Research 2018, 117, 629-641. DOI: https://doi.org/10.1016/j.jbusres.2018.07.021.

[10] Zhang, H.; Liang, X.; Moon, H. Fashion cewebrity involvement in new product development: Scale development and an empirical study. Journal of Business Research 2020, 120, 321-329. DOI: https://doi.org/10.1016/j.jbusres.2020.01.052.

[11] Bertola, P.; Teunissen, J. Fashion 4.0. Innovating fashion industry through digital transformation. Research Journal of Textile and Apparel 2018, 22, 352-369. DOI: https://doi.org/10.1108/RJTA-03-2018-0023.

[12] Lim, J.-S.; Sharkey, T. W.; Heinrichs, J. H. Strategic impact of new product development on export involvement. European Journal of Marketing 2006, 40, 44-60. DOI: https://doi.org/10.1108/03090560610637301

[13] Lindman, M. T. Open or closed strategy in developing new products? A case study of industrial NPD in SMEs. European Journal of Innovation 2002, 5, 224-236. DOI: https://doi.org/10.1108/14601060210451180.

[14] Pitta, D. From market entry to new product development in China: Environmental Systems Control. Journal of Product \& Brand Management 2005, 14, 119-122. DOI: https://doi.org/10.1108/10610420510592608.

[15] Fantazy, K. A.; Salem, M. The value of strategy and flexibility in new product development. Journal of Enterprise Information Management 2016, 29, 525-548. DOI: https://doi.org/10.1108/JEIM-10-2014-0102.

[16] Song, T. S.; Ghobakhloo, M. IT investments and product development effectiveness: Iranian SBs. Industrial Management \& Data Systems 2013, 113, 265-293. DOI: https://doi.org/10.1108/02635571311303578.

[17] Hwang, C.L.; Yoon, K. Multiple Attribute Decision Making: Methods and Applications. New York: SpringerVerlag 1981.

[18] Saisse, R.; Lima, G. Similarity modeling with ideal solution for comparative analysis of projects in the context of the additional brics proposal. Brazilian Journal of Operations \& Production Management 2019, 16, 659-671. https://doi.org/https://doi.org/10.14488/BJOPM.2019.v16.n4.a11. 